\title{
An Electron Microscopic Study of the Location of Teichoic Acid and its Contribution to Staining Reactions in Walls of Streptococcus faecalis 8191
}

\author{
By J. M. GARLAND \\ Department of Anatomy, The Medical School, The University, \\ Newcastle upon Tyne $N E_{\mathrm{I}}{ }_{7} R U$ \\ AND A. R. ARCHIBALD AND J. BADDILEY \\ Microbiological Chemistry Research Laboratory, The University, \\ Newcastle upon Tyne NEI $7 R U$
}

(Received 25 October 1974; revised 3 February 1975)

\begin{abstract}
SUMMARY
The location of the glucosylated teichoic acid in whole cells and isolated walls of Streptococcus faecalis 8I9I has been investigated using ruthenium red, goldlabelled concanavalin A and concanavalin A-peroxidase-diaminobenzidine. Dense laminae were revealed in sections of osmium-fixed walls stained with ruthenium red which corresponded to similar regions stained by uranyl and lead. Such regions were not seen after teichoic acid had been extracted, suggesting that the uptake of stain was by teichoic acid. However, these regions were not labelled on exposure to gold concanavalin A or concanavalin A-peroxidase-diaminobenzidine; these stains indicated that teichoic acid was situated between the dense laminae, although the distribution of stain could have been due to the inability of the concanavalin A stains to penetrate deeply. Chemical binding studies showed that the teichoic acid was the major uranyl binding component in isolated walls, from which it might be inferred that teichoic acid was located in the densely staining regions. However, since osmification significantly increased the binding of uranyl (and lead stains) to non-teichoic acid material, such an inference was not necessarily valid. It is concluded that the presence of teichoic acid can be demonstrated in certain regions of the wall by concanavalin $\mathrm{A}$, but its presence in densely staining regions has not been established. These experiments therefore suggest that teichoic acid may not be intimately associated with the mechanisms that generate contrast patterns in stained sections of cell walls of Streptococcus faecalis.
\end{abstract}

\section{INTRODUCTION}

Acidic, sugar-phosphate polymers (teichoic acids) covalently linked to the mucopeptide are characteristic components of walls of Gram-positive bacteria (Baddiley, 1972). Since electron microscopy of intact cells using standard fixatives and contrasting stains presents a general image of the wall as a multilayered structure (Glauert \& Thornley, 1969), the nature of the relationship between these charged acidic polymers (teichoic acids) and this structure becomes of interest. It might be predicted that the negatively-charged teichoic acid is the major contributor to the binding of positively-charged stain and hence to the production of contrast. Thus, in mutants of Bacillus licheniformis grown under conditions where teichoic acid is not present in the walls, normal contrast patterns are lost (Forsberg et al. 1973). Further, both electron microscopic and electrophoretic studies suggest that teichoic acid is outermost in bacterial walls (Nermut, 1967; Weibull, I973; Neihof \& Echols, 1973). 
Work by Miller (1969) has shown that the wall of Streptococcus faecalis 8I9I, a group D Streptococcus, contains a glucosylated ribitol teichoic acid with rhamnose and galactosamine substitutions. The teichoic acid is readily extractable by relatively gentle procedures which break either the phosphate backbone (alkaline hydrolysis) or the ribitol moiety (periodate oxidation). Both isolated walls and teichoic acid are precipitated by concanavalin $\mathbf{A}$ (Archibald \& Coapes, I97I), a plant lectin specifically reactive to $\alpha$-glucoside, $\alpha$-mannoside and a small number of related residues, showing that glucose residues are exposed in suitable configurations for specific reaction. These observations therefore suggested (Archibald \& Coapes, 197I) that the walls may be amenable to electron microscopic and chemical correlations. This paper reports the gross structure of intact and isolated walls and their interaction with two labels considered specific for the teichoic acid - gold-labelled concanavalin A (gold con A) (Garland, 1974a) and concanavalin A-peroxidase-diaminobenzidine (con A-peroxidase) - as well as with ruthenium red, a stain reportedly specific for acid polysaccharides (Anderson, 1968) and teichoic acids (Burdett \& Rogers, 1972). The images produced by two normal stains, uranyl acetate and basic lead citrate, are compared with their binding to isolated walls, before and after extraction of the teichoic acid, as determined by scintillation counting and atomic absorption spectroscopy. Preliminary reports on part of these investigations have been presented elsewhere (Garland, 1974a, b). Bauer, Farr \& Horisberger (1974) subsequently described a similar study, also using gold con A, and concluded that teichoic acid is situated diffusely in the wall of $S$. faecalis. A similar conclusion was reached by Millward \& Reaveley (I974) in an electron microscopic study of walls of B. licheniformis and Staphylococcus aureus.

\section{METHODS}

Preparation of cell walls. Cell walls were prepared from a $15 \mathrm{~h}$ fermenter culture of $S$. faecalis $8 \mathrm{I} 9 \mathrm{I}$. Growth medium contained I \% tryptone, $0.5 \%$ yeast extract, $0.5 \% \mathrm{KH}_{2} \mathrm{PO}_{4}$ and I $\%$ glucose. Cells were harvested after I $6 \mathrm{~h}$ growth at $37{ }^{\circ} \mathrm{C}$, washed once in $0.85 \%$ $\mathrm{NaCl}$ and disrupted in a Braun disintegrator using No. 2 Ballotini beads for $2.5 \mathrm{~min}$. The resulting suspension was spun at $17000 \mathrm{~g}$ for $30 \mathrm{~min}$ and the supernatant discarded. Further purification was restricted to a series of 6 washes each in $0.85 \% \mathrm{NaCl}$ and distilled water, using sedimentations of $15000 \mathrm{~g}$ for $20 \mathrm{~min}$, all operations being carried out at $4{ }^{\circ} \mathrm{C}$. The final wall preparation was freeze-dried and weighed.

For nuclease treatment, pasteurized walls were suspended at a concentration of $10 \mathrm{mg} / \mathrm{ml}$ in 0.1 M-tris- $\mathrm{HCl}$ buffer $\mathrm{pH} \mathrm{7 \cdot 2.} \mathrm{Small} \mathrm{quantities} \mathrm{of} \mathrm{both} \mathrm{RNAase} \mathrm{and} \mathrm{DNAase} \mathrm{(Sigma)}$ were added, and the suspension was incubated at $37^{\circ} \mathrm{C}$ for $6 \mathrm{~h}$ followed by centrifugation and two washes in distilled water.

Whole cells for comparison with the isolated walls were grown in the same medium in small flasks at $37^{\circ} \mathrm{C}$. For gold con A labelling, glucose was replaced by fructose and the culture was washed once in $0.85 \%(\mathrm{w} / \mathrm{v}) \mathrm{NaCl}$ before exposure to the label.

Electron microscopy. Standard fixation was essentially as described by Highton (1969). After fixation in $1 \%$ osmium cyanide in R-K buffer (Ryter \& Kellenberger, 1958) for I4 $\mathrm{h}$ at room temperature, specimens were embedded in agar and stained for $2 \mathrm{~h}$ in $0.5 \%$ uranyl acetate in distilled water. Samples were dehydrated in graded acetone steps and embedded in Spurr resin (TAAB Laboratories, Reading, Berkshire). Silver-grey sections were cut on an LKB Microtome using a diamond knife, and all lead staining performed on the grids by application of a drop of lead citrate (Reynolds, I963) for Io s followed by immediate washing in a stream of clean distilled water. Sections were viewed on a JEM roou microscope 
equipped with goniometer stage and operated at $80 \mathrm{kV}$ using instrumental magnifications of 25000 unless otherwise stated. Catalase crystal calibration showed less than I \% error in recorded magnification. Microdensitometry was performed with a Joyce-Loebl recording microdensitometer (Joyce-Loebl, Gateshead, County Durham) using a slit-width of $100 \mu \mathrm{m}$ and scale magnification of 100 . All recordings were taken from walls considered to be cut orthogonally.

Histochemical methods. Three histochemical methods potentially specific for teichoic acid were used: gold con A, con A-peroxidase and ruthenium red.

Preparation of gold con A has been previously described (Garland, 1974a). For labelling, 5 to $10 \mathrm{mg}$ dry wt of walls were exposed to I \% gold con $\mathrm{A}$ in $0.85 \% \mathrm{NaCl}$ for $30 \mathrm{~min}$ at room temperature, followed by a single wash. After standard fixation with uranyl acetate staining, sections were stained by lead citrate.

The con A-peroxidase method relies on the interaction of bivalent con $\mathrm{A}$ with a sugar moiety on the peroxidase molecule after reaction of one of the con A binding sites with substrate; the peroxidase is then available to catalyse the reaction between hydrogen peroxide and diaminobenzidine, resulting in an osmiophilic deposition product. The method described by Huet \& Hertzberg (1973) was followed, using the same quantities of wall as for gold con A and adjusting other quantities suitably. In both methods controls included the addition of a roo-fold excess of the specific inhibitor of con A reactions, $\alpha$-methyl glucoside, to the initial con A binding step.

The specificity of ruthenium red for acidic polysaccharides has been described by Anderson (1968). The method of Burdett \& Rogers (1972) was followed, with minor adjustments as in the text.

After staining by any of the above methods, samples were embedded by the standard procedure with or without uranyl acetate staining as indicated.

Phosphate determination. Inorganic phosphate was determined by ascorbic-molybdate (Chen, Toribara \& Warner, 1956) after ashing in a small volume of a $3: 2(\mathrm{v} / \mathrm{v})$ solution of conc. $\mathrm{H}_{2} \mathrm{SO}_{4}$ and $60 \%(\mathrm{v} / \mathrm{v})$ perchloric acid.

Extraction of teichoic acid. Two procedures were employed: (i) Periodate oxidation. Small samples of wall of known weight ( 5 to $20 \mathrm{mg}$ ) were oxidized overnight at room temperature in dark bottles with $0 . \mathrm{I}$ M-sodium metaperiodate. Residual periodate was removed by the addition of ethylene glycol and after a single wash in distilled water the walls were either freeze-dried or used immediately. (ii) Sodium hydroxide extraction. Similar quantities of wall were extracted with $0.5 \mathrm{M}-\mathrm{NaOH}$ at $37^{\circ} \mathrm{C}$ for $\mathrm{I} \mathrm{h}$ followed by neutralization with $\mathrm{HCl}$ and a single wash in distilled water.

Isolation of teichoic acid. Pasteurized walls were suspended at a concentration of $10 \mathrm{mg} / \mathrm{ml}$ in $0.1 \mathrm{M}$-tris- $\mathrm{HCl}$ buffer $\mathbf{p H ~ 7 \cdot 2 . ~ S m a l l ~ q u a n t i t i e s ~ o f ~ D N A a s e ~ a n d ~ R N A a s e ~ ( S i g m a ) ~ w e r e ~}$ added and the suspension incubated at $37^{\circ} \mathrm{C}$ for $6 \mathrm{~h}$, followed by two washes in distilled water. Teichoic acid was extracted by sodium hydroxide as above. After neutralization, the extract was dialysed against the above buffer and run through a $34 \times \mathrm{I} \cdot 8 \mathrm{~cm}$ column of Sephadex G-25. All phosphate was eluted in the void volume, which was collected and assayed for phosphate and for extinction at 260 and $280 \mathrm{~nm}$.

Borohydride reduction. Periodate-oxidized walls were reduced overnight at room temperature in $\mathrm{O} \cdot \mathrm{I} \mathrm{M}$-sodium borohydride in $0.05 \mathrm{M}$-sodium carbonate buffer $\mathrm{pH} 9$, followed by two washes in distilled water.

Uranyl acetate binding. Known quantities of the various wall and teichoic acid samples were exposed to $0.5 \%$ uranyl acetate for $30 \mathrm{~min}$ at room temperature. Walls were washed twice in water, resuspended in a known volume, and known duplicate amounts counted in 
$5 \mathrm{ml}$ Dioxan scintillant using a Packard scintillation counter. Counts were accumulated to at least $2 \times 10^{3}$. For the teichoic acid samples, known amounts of uranyl acetate and sample solution were mixed and left to precipitate at room temperature. The amount bound to the precipitate was determined by the loss of counts in the supernatant after centrifugation.

Lead binding. Wall samples of known weight were exposed to $\frac{1}{5}$ dilution of the lead citrate stain used for the electron microscopy. After $30 \mathrm{~min}$ at room temperature, the samples were washed twice in distilled water and ashed with a small quantity of conc. $\mathrm{HNO}_{3}$ in acidcleaned hard-glass tubes. The resulting colourless solution was made up to a known volume (Io to $20 \mathrm{ml}$ ) with distilled water, and samples run through a Pye SP 90 atomic absorption spectrometer, calibrated at each run with standard lead solutions.

Extinctions. These were measured at $620 \mathrm{~nm}$ in $\mathrm{I} \mathrm{cm}$ path-length cells.

Chemicals. All chemicals were of Analar grade, from BDH. Concanavalin A and horseradish peroxidase type IV were obtained from Sigma. Scintillant contained I $30 \mathrm{~g}$ naphthalene, $8 \mathrm{~g}$ 2,5-diphenyloxazole and $0.3 \mathrm{~g}$ dimethyl I,4-bis-(2-(4-methyl 5-phenyloxazolyl)) benzene (Koch-Light) per litre dioxan.

\section{RESULTS}

Electron microscopy of whole cells

Standard fixation. Figure I shows $S$. faecalis 8I 9 I cells in early stationary phase after standard fixation and staining with lead citrate. Microdensitometer traces are given in Fig. 4. The wall profile (Fig. I) closely resembles that described for another $S$. faecalis (Higgins \& DaneoMoore, 1972): an outer dark layer with a ragged surface, a middle lighter layer, and an inner dark layer from which the plasma membrane cannot be distinguished. However, an irregular light region separates inner wall from cytoplasm proper, and this is considered to be the middle lamina of a trilaminar plasma membrane. Excrescences of the outer layer in the region of developing septa (arrowed) appeared to separate into two as septation progressed and correspond to equatorial growth bands (Shockman \& Martin, 1968). In a significant number of sections a thin dark layer was observed in the centre of the middle layer (not illustrated but recorded in the microdensitometer trace of the section used in Fig. 4).

Ruthenium red staining. Fixation in the presence of ruthenium red produced less satisfactory preservation of internal structure, but the wall profiles were similar (Fig. 4, b and c) and the dark layer in the centre of the middle layer appeared with greater frequency. No significant new detail was revealed by the further addition of uranyl acetate or lead citrate, singly or sequentially. Microdensitometer measurements were made on at least ten different sections of wall, from between five and eight cells which had been exposed to each staining procedure and selected randomly for visibility of the cytoplasmic light layer as an indication of an orthogonal section (Table I). As the outer layer was excessively variable due to its raggedness, only the inner and middle layers have been presented. Each staining procedure gave separate thicknesses, but wherever lead was used the inner and middle layers were comparable and consistently thicker, irrespective of exposure to additional stains (Table I, lines 3, 4 and 6).

Gold con $A$ labelling. Cells grown in glucose-free medium were rapidly precipitated by both con $\mathrm{A}$ and gold con $\mathrm{A}$. However, sectioning showed all cells to be devoid of label although strings of gold particles occurred frequently in the background. Some specimens contained long wisps of string-like material embedded with the cells (Fig. 2); serial sectioning showed that these extended through several sections. This material has always been 

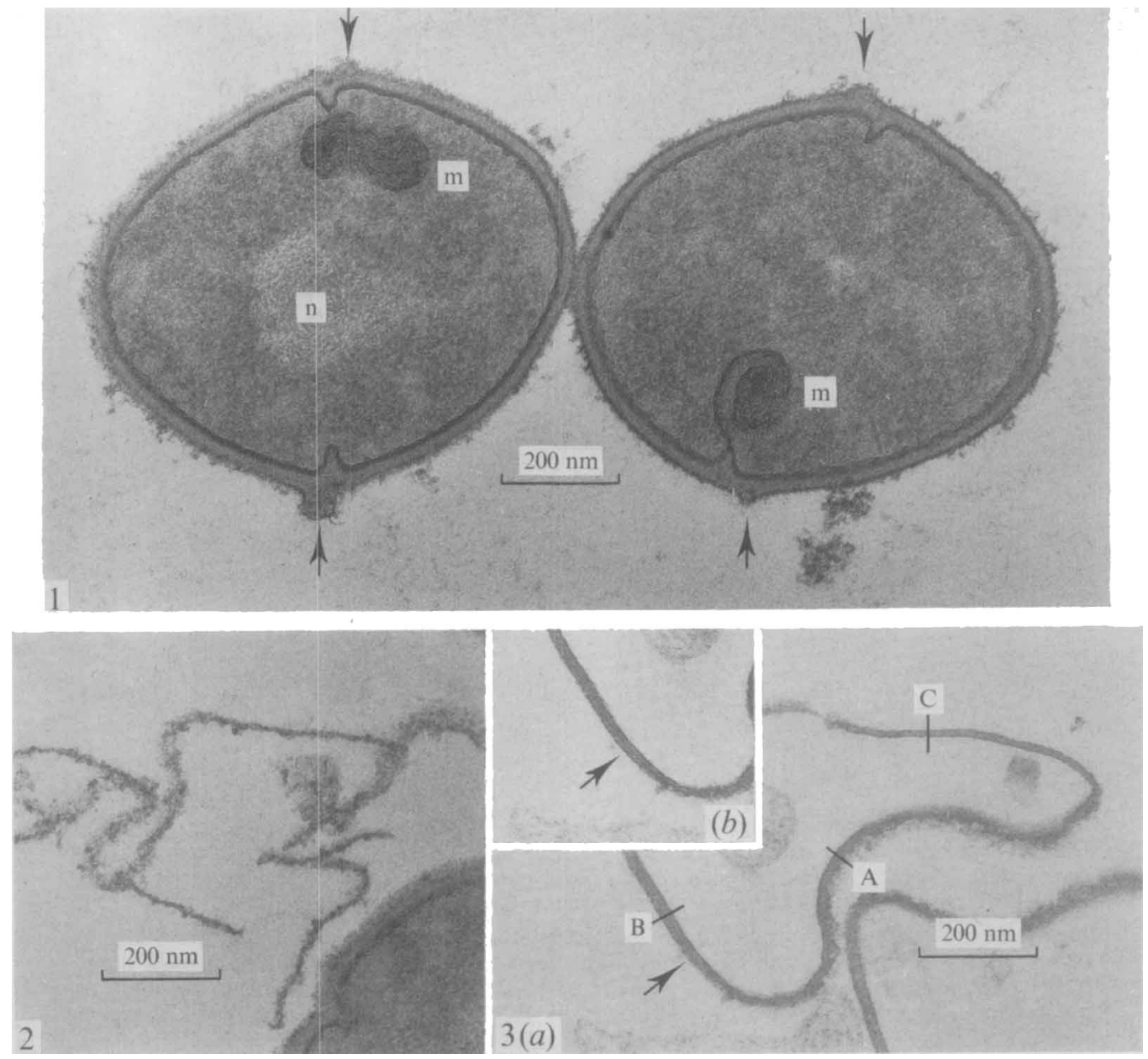

Fig. I. Thin section of osmium-fixed S. faecalis 8I9I after uranyl acetate and lead citrate staining. Walls have a ragged outer surface with an underlying thin layer of high contrast. A dark layer is not present in the middle layer of these walls (see Fig. 2), but the equatorial growth bands are well developed (arrowed). The inner wall layer is very positively contrasted, and abuts on an irregular cytoplasmic profile. A cell membrane is not distinguishable although a thin light layer occurs adjacent to the cytoplasm. $\mathrm{m}$, Mesosome; $\mathrm{n}$, nuclear material.

Fig. 2. Material associated with whole cells. Such material became heavily labelled with gold con A. The significance of the apparent double track profile is unknown.

Fig. 3. Wall preparation after standard osmium-uranyl-lead staining. (a) Wall profiles recognized are type A, type B and type C. (b) Same section as (a), tilted through $20^{\circ}$. A type B profile with central dark layer appears in a region previously similar to a type A (arrowed). Microdensitometer traces from the type $\mathrm{B}$ and $\mathrm{C}$ profiles are given in Fig. 5, $\mathrm{b}$ and $\mathrm{c}$.

encountered with whole cells, and could be cell membrane material released by lysis, containing glucosylated glycerol teichoic acid (Wicken \& Baddiley, 1963). However, it would appear unlikely that the amount of cell lysis occurring during labelling could account for this material saturating the gold colloid (see Table 2, line 3). 

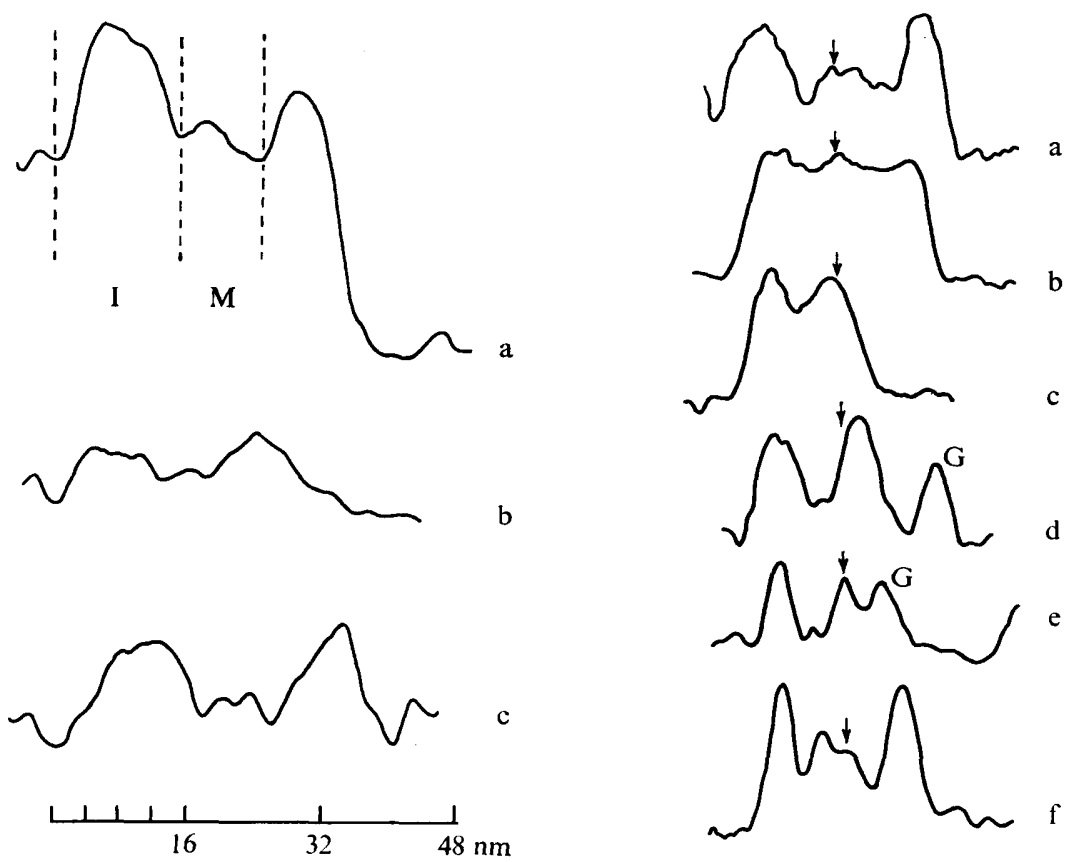

Fig. 4.

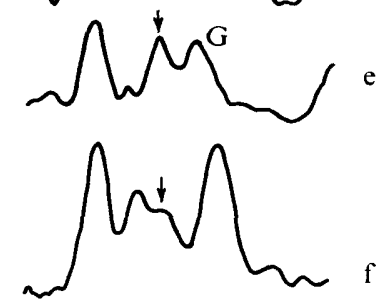

Fig 5 .

Fig. 4. Microdensitometer profiles of whole-cell walls. a, Standard osmium-uranyl-lead staining. Dashed lines show limits measured for inner (I) and middle (M) layers, the latter containing a central dark layer. b, Osmium-ruthenium red stained cells. c, Osmium-ruthenium red followed by lead citrate on the section. Measurements are given in Table $\mathrm{r}$.

Fig. 5. Microdensitometer profiles from the isolated wall preparations. a, Walls stained with ruthenium red, uranyl and lead. The arrow marks the relative position of the central dark layer. b, A type B profile from Fig. 3(b). c, A type C profile from Fig. 3(b). d, Profile from the gold con A-labelled walls shown in Fig. 8. G, gold particle. e, Profile from the gold-labelled type C region shown in Fig. 13. f, Profile from the unlabelled type B region in Fig. 13.

Table I. Variation in thicknesses of wall layers in S. faecalis according to staining procedure

All cells were fixed in osmium cyanide (Highton, 1969). Uranyl acetate staining was performed before embedding and all lead staining performed on the sections using lead citrate (Reynolds, 1963).

Stain
Ruthenium red
Ruthenium red + uranyl acetate
Ruthenium red + uranyl acetate+
lead citrate
Ruthenium red + lead citrate
Uranyl acetate
Uranyl acetate + lead citrate

$\begin{array}{lc}\text { Inner (I) } & \text { Middle (M) } \\ \text { I0.8 (0.8) } & 6.9(0.3) \\ 14.8(0.6) & 7.6(0.4) \\ 17.7(\mathrm{I} \cdot 6) & 9.2(\mathrm{I} \cdot 9) \\ & \\ 16.0(\mathrm{I} \cdot 8) & 9.6(\mathrm{I} \cdot 2) \\ 13.6(0.7) & 5.5(0.8) \\ 15.9(0.4) & 9.1(0.6)\end{array}$

* Measurements (at least 10 ) were taken from the cytoplasmic light layer to the termination of the first density peak (layer 6 in Fig. 6) for the inner layer, and from this to the commencement of the outer density peak (layer 2 in Fig. 6) for the middle layer (see Figs. 4 and 6). Standard deviations are given in parentheses. $\mathrm{I}$ and $\mathrm{M}$ refer to the microdensitometer tracings in Fig. 4. 


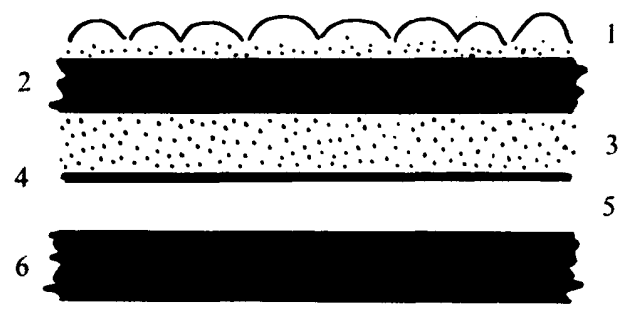

Fig. 6. Contrast profile of stained walls of $S$. faecalis 8I9I. Three dense layers appear in sections (layers 2, 4 and 6). Layer (I) appears to be labile to manipulation, leaving an outer surface in isolated walls corresponding to dense layer (2) itself or dense layer (4), but with remnants of layers (I) or (3) still attached, and which label with gold-con A (stippled). The dense layer (6) merges with the plasma membrane. Membrane teichoic acid (Wicken \& Baddiley, 1963; Jones \& Shattock, 1960) may be situated in this layer (Huis in't Veld \& Linssen, 1973) and may even penetrate the wall (van Driel et al. 1973).

\section{Table 2. Extraction of phosphate from $S$. faecalis 819I walls}

Phosphorus content was $2.4 \%$ dry mass for untreated walls, estimated by ascorbic-molybdate after ashing, and $1 \cdot 9 \%$ for nuclease treated walls.

Treatment of walls

$0.5 \mathrm{M}-\mathrm{NaOH}\left(\mathrm{I} \mathrm{h}, 37^{\circ} \mathrm{C}\right)$

$0 \cdot \mathrm{I} \mathrm{M}^{-\mathrm{NaIO}_{4}}\left(18 \mathrm{~h}, 18^{\circ} \mathrm{C}\right)^{*}$

Distilled water $\left(18 \mathrm{~h}, 18^{\circ} \mathrm{C}\right)$

Fixed in glutaraldehyde $\dagger$ or heated to

$60{ }^{\circ} \mathrm{C}$ in distilled water before incubation

( $18 \mathrm{~h}$, at $18^{\circ} \mathrm{C}$ in distilled water)

Combined RNAse, DNAse $\left(6 \mathrm{~h}, 37^{\circ} \mathrm{C}\right)$

$\begin{array}{cc}\begin{array}{c}\text { Dry mass loss } \\ (\%, w / w)\end{array} & \begin{array}{c}\text { Phosphate loss } \\ (\%, w / w)\end{array} \\ 61 & 96 \\ 40 & 65 \\ 25 & 44 \\ \text { Nil } & \text { Nil } \\ & \\ & \\ & \\ & 29\end{array}$

* No further extraction occurred at 24 or $48 \mathrm{~h}$.

$\dagger$ Fixed in $0.5 \%$ glutaraldehyde, $\mathrm{I}$ h at room temperature in sodium cacodylate buffer $\mathrm{pH} 8$.

\section{Electron microscopy of isolated walls}

Standard fixation. Enzymic and detergent cleaning of disrupted cell walls was avoided, to reproduce as far as possible conditions similar to those employed with whole cells. The preparation was $96 \%$ large wall fragments, often enclosing small quantities of poorlycontrasted cell debris; the remaining $4 \%$ consisted mainly of unbroken cells. After standard fixation and staining with lead, three kinds of wall profile were seen in sections (Fig. $3 a$ ) represented diagrammatically in Fig. 6: type A, smooth inner dark layer but very ragged outer layer; type B, smooth dark layers on either side, enclosing a lighter layer (layers 2 to 6 in Fig. 6); and type C, a much thinner profile than either of the above, bounded by smooth dark layers. In types A and B a thin dark layer was frequently present in the middle of the profile; in certain areas the wall had peeled apart from this middle layer, leaving ragged material behind (Fig. 7). Some type A profiles could be changed into type B by tilting the section (Fig. $3 b$ ), but it could not be shown that some type A profiles were merely tangential views of type B; indeed, evidence such as that in Fig. 7, where a B profile appears to form an $A$ profile on the extreme left, suggested that they were not. Microdensitometry showed that the type $\mathrm{C}$ profile corresponded very closely with that of a 'half-thickness' of wall from the inner side to the middle dark layer (Fig. 5), the inner periplasmic side being identified by the presence of septa. Additionally, these measurements were very similar to those 

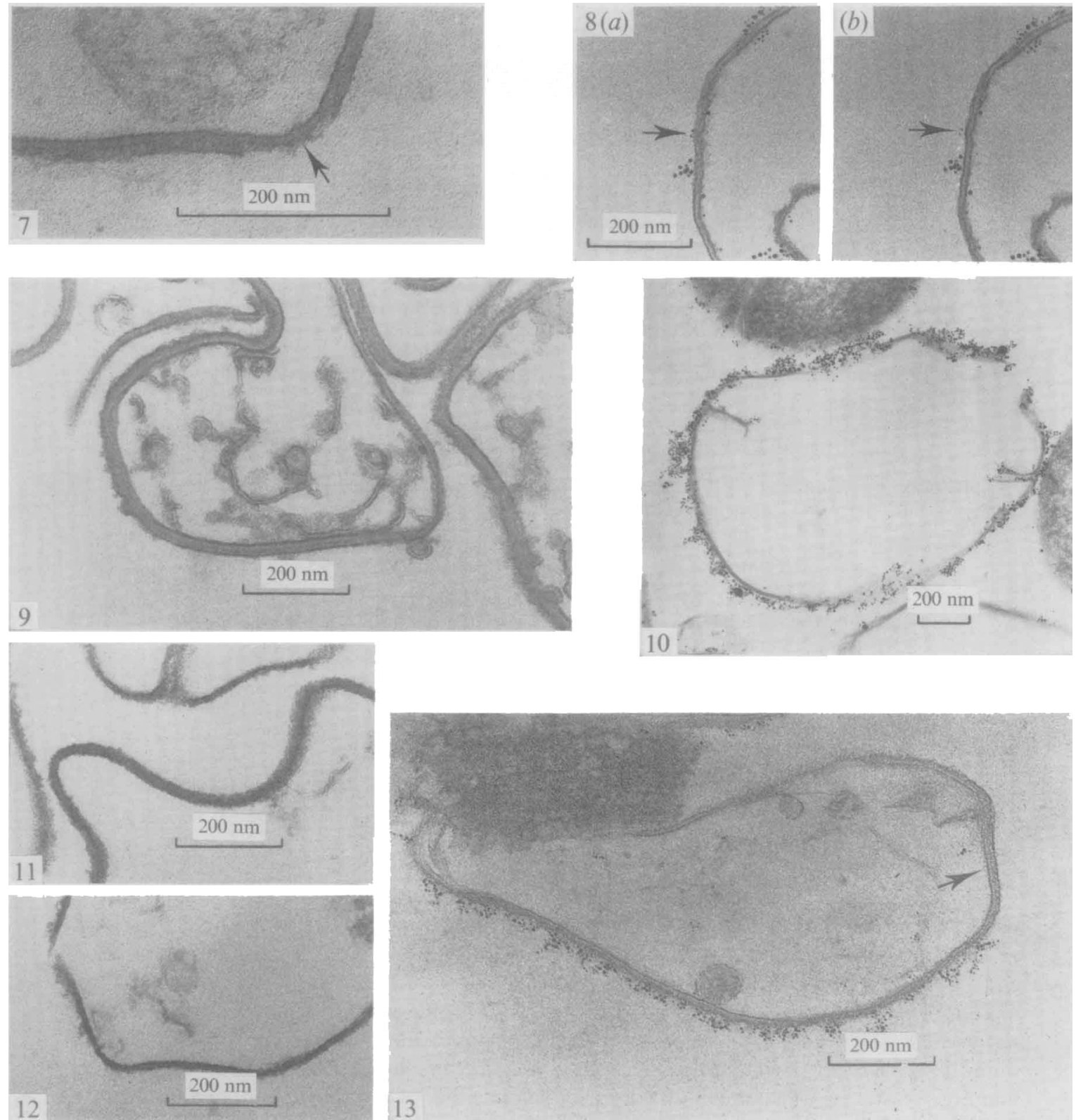

Fig. 7. Wall disintegration. A discontinuity has occurred between two type B regions where a type C profile (arrowed) now occurs, with amorphous material still adherent. The central dark layer responsible for the type $\mathrm{C}$ profile tends to be obscured in the neighbouring $\mathrm{B}$ regions.

Fig. 8. (a) Gold con A label on a type $C$ profile with intervening unresolved area. (b) The same area tilted through $20^{\circ}$. The previously unresolved area is clearly a continuation of the $\mathrm{C}$ profile (see Fig. 5d) and is labelled by two gold particles (arrowed).

Fig. 9. Isolated wall preparation stained with ruthenium red. Distinct membrane-like structures are seen.

Fig. Io. Walls labelled with gold con A. Labelling is very patchy but there is a distinct preference for one side of the wall.

Fig. I I. Walls stained with con A-peroxidase. The image is coarse and without ultrastructural detail.

Fig. I2. As for Fig. 11, with $\alpha$-methyl glucoside inhibition. Walls are slightly thinner.

Fig. I3. A length of (tilted) type $C$ profile is labelled with gold con $A$ whilst a type B profile (arrowed) remains unlabelled. See Fig. 5, e and $\mathrm{f}$. 
positioning the dark layer in the middle layer of whole-cell walls. Thus, the type $\mathrm{C}$ profile appeared to originate from type B by loss of the dense layer (2) shown in Fig. 6 together with the underlying light layer (3).

Ruthenium red staining. There was no significant alteration in profiles with ruthenium red staining, whether accompanied by other stains or not (Figs. $5 \mathrm{a}$ and 9). However, cell debris had greatly increased contrast and structures interpreted as membrane fragments could be clearly seen.

Gold con A labelling. Walls were heavily, but patchily, labelled with gold con A (Fig. Io), there being a distinct preference for one side, usually the outer. The underlying wall profiles were however different from the above in being mostly types B and C, many indistinct regions being capable of conversion to either of these by tilting the section (Fig. $8 a, b$ ). An apparent contrast enhancement of the dark layers appeared to be an optical artefact, on the basis of relative peak heights recorded (Fig. 5 a) although the material was not considered suitable for exact quantitative microdensitometry. Gold particles extended relatively far from the walls, and both types of profile were labelled without apparent preference, despite appearances such as in Fig. I 3 where there appears to be a preference for a type $\mathrm{C}$ profile cut obliquely. All labelling was abolished in the presence of $\alpha$-methyl glucoside.

Concanavalin A-peroxidase-diaminobenzidine labelling. Wall preparations rapidly blackened on addition of diaminobenzidine and hydrogen peroxide after exposure first to con A and then to peroxidase. Colour development was greatly retarded if $\alpha$-methyl glucoside had been present during the con A or peroxidase binding steps. Sections showed that con A-peroxidase staining resulted in a general increase in density and thickness of the walls but finer detail was obscured (Figs. I I and I2).

\section{Electron microscopy of extracted walls}

Walls extracted by either periodate or sodium hydroxide were generally thinner than before, always of uniform density throughout irrespective of staining procedure (Fig. 14), and nearly all cell debris had disappeared. Extracted walls were refractory to gold con A labelling, although hydroxide-extracted walls appeared to retain small quantities of label usually on the inside surface (Figs. 16 and 17 ). A distinctly different situation arose with con A-peroxidase-diaminobenzidine labelling. Whereas hydroxide-extracted walls were unlabelled (Fig. 15), periodate-oxidized walls darkened more rapidly than controls, even those including $\alpha$-methyl glucoside, and sections showed a corresponding heavy labelling (Fig. I8). This was interpreted as a consequence of the extraction method, such as the generation of reactive aldehyde groups, for if the oxidized walls were reduced with borohydride, labelling did not occur (Fig. 19).

\section{Chemical studies}

All estimations were performed at least twice on separate material, and related to dry mass by both extinction measurement of the suspensions and weight after freeze-drying. Good agreement was found.

Phosphate extraction. Table 2 shows the wall composition and extent of phosphate extraction. Walls clearly possessed some autolytic activity, which was prevented by glutaraldehyde fixation or pasteurization. Such treatments did not significantly alter any results, however, presumably due to the relatively short times walls were exposed to manipulation and to a general lability of extracted walls that was unaffected by either treatment, whether before or after extraction.

Uranyl acetate binding. Although not of natural isotope composition, commercial uranyl 

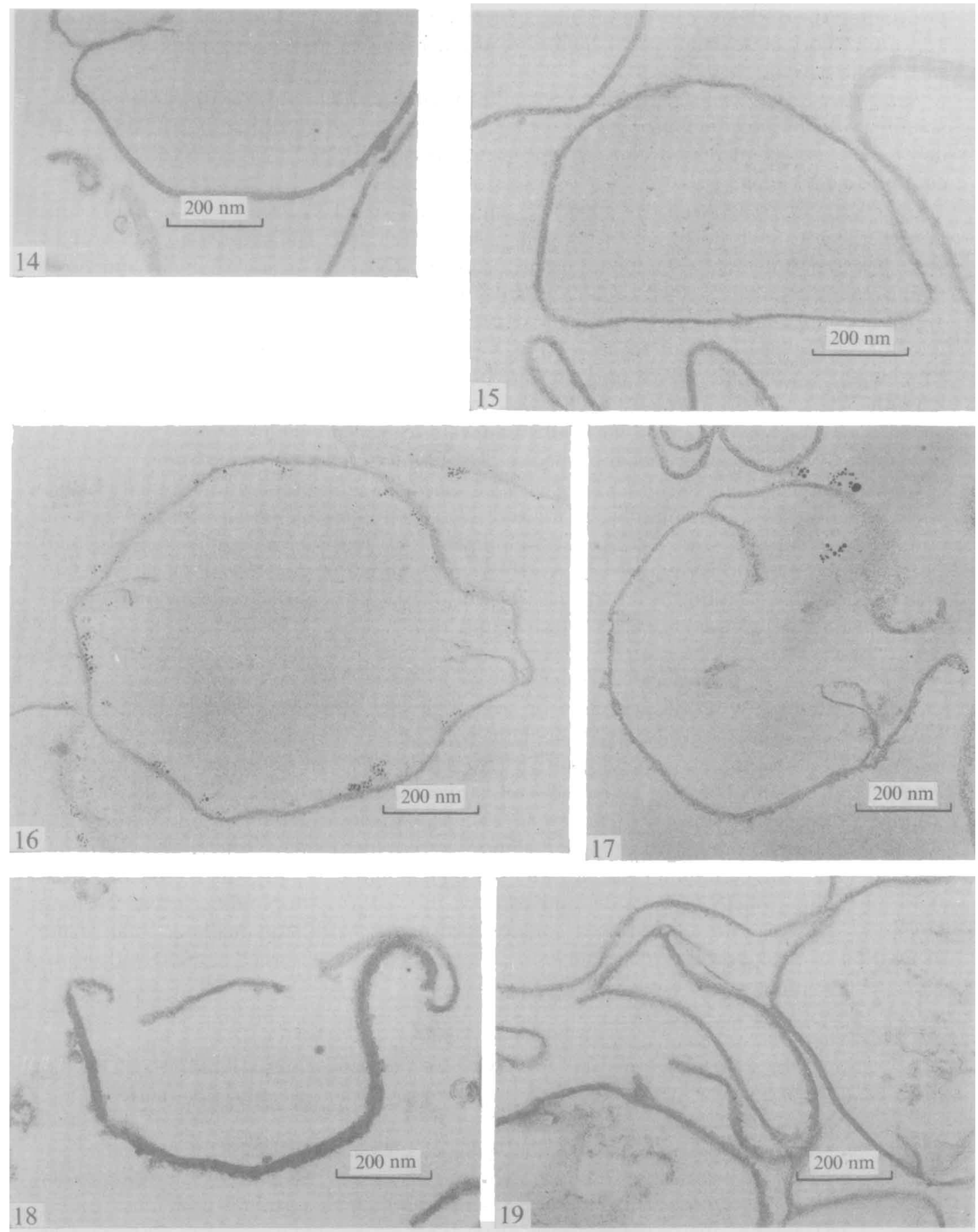

Fig. I4. Sodium hydroxide-extracted walls stained with ruthenium red and uranyl. All lamination has disappeared (see Fig. 9).

Fig. 15. Sodium hydroxide-extracted walls stained by con A-peroxidase.

Fig. I6. Sodium hydroxide-extracted walls exposed to gold con A. Small but significant amounts of gold have been retained but on the inside surface (see Figs. 8, IO and 13).

Fig. 17. Periodate-extracted walls exposed to gold con A. No labelling has occurred.

Fig. I 8. Periodate-extracted walls stained by con A-peroxidase. Walls are heavily stained, especially on the outer surface where blebs of reaction product occur (see Figs. II and I5).

Fig. 19. Periodate-extracted walls reduced with borohydride before staining with con A-peroxidase. 
Table 3. Principal decay products of uranium

Table constructed from information provided by the Radiochemical Centre, Amersham, Buckinghamshire.

$\begin{array}{lccccc}\text { Element } & { }_{90} \mathrm{Th}^{231} & { }_{89} \mathrm{Ac}^{227} & { }_{87} \mathrm{Fr}^{223} & { }_{82} \mathrm{~Pb}^{211} & { }_{81} \mathrm{Tl}^{207} \\ \begin{array}{c}\text { Energy of principal } \\ \beta \text {-emissions (MeV) }\end{array} & 0.3 & 0.04 & \mathrm{I} \cdot \mathrm{I} 5 & \mathrm{I} \cdot 36,0.5 & \mathrm{I} \cdot 44,0.53\end{array}$

Table 4. Binding of uranyl salt to $S$. faecalis wall preparation

\begin{tabular}{|c|c|c|c|c|}
\hline \multirow[b]{2}{*}{ Extraction } & \multirow{2}{*}{$\begin{array}{l}\text { Fixation after } \\
\text { extraction but } \\
\text { before uranyl }\end{array}$} & \multicolumn{2}{|c|}{$\begin{array}{l}\text { Absolute counts* in } \\
\text { typical experiment (d.p.m.) }\end{array}$} & \multirow{2}{*}{$\begin{array}{l}\text { Counts in intact } \\
\text { wall due to binding } \\
\text { to unextracted } \\
\text { material }(\%)\end{array}$} \\
\hline & & Unextracted & Extracted & \\
\hline $\begin{array}{l}\mathrm{NaOH} \text {, distilled water } \\
\text { washed } \dagger\end{array}$ & None & 245 & IOI & 17 \\
\hline $\mathrm{NaOH}$ & None & 377 & 201 & $2 \mathrm{I}$ \\
\hline $\mathrm{NaOH}$ & Osmium & 502 & 427 & 33 \\
\hline Periodate & None & 403 & I 55 & 23 \\
\hline Periodate & Osmium & 560 & 408 & 44 \\
\hline None (nuclease treated) & None & 378 & - & - \\
\hline None (nuclease treated) & Osmium & 454 & - & 一 \\
\hline
\end{tabular}

acetate contains sufficient radioactivity to be measurable (approx. $0.7 \mu \mathrm{Ci} / \mathrm{mmol}$ ). The relative abundance of the radioactive decay products was unknown but Table 3 lists the principle emissions considered effective for scintillation counting. Because of the wide spectrum of energies, all counts from a wide window were taken $(0.5$ to infinity, $10 \%$ gain) which included about $95 \%$ of total registerable counts. (Despite the presence of suitable high-energy emissions, Cerenkov counting could not be used, presumably because of a large colour absorbance of the uranyl salt at $425 \mathrm{~nm}$.) Channels ratio determinations on the type of material counted using set windows showed negligible spectral shifts for most samples except those osmicated, where moderate quenching was present. Binding studies were performed on the different samples at the same times and were repeated on several occasions. Counts recorded were comparable but not identical. A typical set of results is given in Table 4. Consistently, extraction of the teichoic acid greatly reduced uranyl uptake and, after allowing for the composition of unextracted wall (Table 2), only some $20 \%$ of counts in unextracted wall could be ascribed to phosphate-free residue. As very similar figures were recorded for nuclease-treated walls, the majority of counts in unextracted walls could be ascribed to teichoic acid. Osmification, however, considerably increased the contribution made by phosphate-free residue (lines 3 and 5, Table 4 ) and increased the amount of uranyl bound in all specimens.

Purified teichoic acid. Nucleic acid phosphorus was less than $4 \%$ of total phosphorus in purified teichoic acid. Addition of uranyl caused almost immediate precipitation and no phosphorus could be detected in the supernatant after removal of the precipitate. Approximately $29 \mu \mathrm{g}$ uranyl were bound $/ \mu \mathrm{g}$ phosphorus, giving an atom ratio of $\mathrm{U}$ to $\mathrm{P}$ of 4 . Uranyl also precipitated the nucleic acids released by nuclease treatment and gave the same atom ratio.

Lead binding. Figures from a typical experiment on osmium-fixed samples are given in Table 5. Osmium by itself appeared to contribute little to lead binding, the most significant 


$\begin{array}{ccc}\text { Table 5. Binding of lead to } S \text {. faecalis 819I } & \text { wall preparation } \\ \text { Extraction } & \begin{array}{c}\text { Fixation after extraction } \\ \text { and before exposure to lead }\end{array} & \begin{array}{c}\text { Lead bound } \\ (\mu \mathrm{g} / \mathrm{mg} \text { dry wt) }\end{array} \\ \mathrm{None} & \text { Osmium } & 32 \\ \mathrm{NaOH} & \text { Osmium } & 28 \\ \mathrm{None} & \text { Osmium and uranyl } & 190 \\ \mathrm{NaOH} & \text { Osmium and uranyl } & 170 \\ \mathrm{None} & \text { Uranyl } & 228 \\ \mathrm{NaOH} & \text { Uranyl } & 1 \mathrm{I} 6\end{array}$

factor being uranyl staining. There was relatively little difference between extracted and unextracted walls. Extracted samples were however quite labile (up to $25 \%$ loss in mass), and lead binding studies were not pursued. Specimens from both the uranyl and lead binding experiments, taken for electron microscopy, embedded poorly in resin and could not be sectioned. However, unextracted walls exposed to uranyl before osmium fixation in a separate experiment showed similar contrast patterns to those stained after fixation.

\section{DISCUSSION}

Thin sections of intact and isolated walls of $S$. faecalis 819I exhibited distinct alternations in contrast when positively stained with uranyl and lead. Whilst measurements differed according to which stains were applied (Table I, and Figs. 4 and 5) all metal stains and ruthenium red gave similar profiles. Regions staining densely disappeared, however, after the phosphate was extracted and this was accompanied by a loss of reactivity to gold con A. However, the distribution of gold label in unextracted walls was patchy, often extending a long way from the wall, and could not be correlated with the presence of a densely stained region. Evidence was found throughout the study that the walls could be damaged during manipulation, for whole cells were not labelled by con A but labelled material was found with them, although examination of cells still in contact after division did not show any extra layers at the point of attachment (Fig. I); profiles of isolated walls indicated that significant amounts of material were frequently missing (Figs. 5 and 7), and bound uranyl was selectively lost on washing (Table 4). These observations therefore suggest that material reactive to con A was situated on either side of the densely staining region represented by layer (2) in Fig. 6. However, gold particles are large (I4 to $40 \mathrm{~nm}$ diam) and sites within the wall could therefore be inaccessible to gold con A. The peroxidase-diaminobenzidine labelling showed very little variation in density throughout the wall; as it also gave a positive reaction in periodate-extracted walls, it may therefore be an unreliable stain. None of the staining regimens therefore quite excludes the presence of teichoic acid in the dense-staining regions. The binding studies (Tables 2, 4 and 5) indicate that the teichoic acid contributed significantly to uranyl binding in walls, and indeed, isolated teichoic acid avidly bound uranyl in solution. Lead binding was clearly dependent upon previous exposure to uranyl (Table 5). Consistently, osmification increased uranyl binding to all wall samples by increasing the binding to non-phosphate residue. This material presumably forms osmates with the peptidoglycan (Cook \& Bugg, 1973; Highton et al. 1968; Kroplein, 1974) which then binds uranyl and lead cations (Reynolds, 1963). Additional binding sites could be presented by glutamine and lysine in the peptidoglycan (Schleifer \& Kandler, 1972).

Thus, these experiments have shown no direct relationship between teichoic acid and densely stained regions in the cell wall. Relatively few studies correlating the presence of 
teichoic acid with contrast patterns in bacterial walls have been reported. Nermut (1967) located teichoic acid in the outer layer of stained walls of Bacillus megaterium on the basis of different contrast profiles obtained after chemical extraction. Weibull (1973) deduced similar precise localizations from images of unfixed walls and argued that dense regions were generated by electron-scattering from phosphorus atoms. However, in neither of these studies were chemical correlations reported. Similarly, in their recent study of $S$. faecalis 8I9I, Bauer et al. (1974) do not report chemical studies and do not discuss the significance of the densely staining regions evident in their micrographs. The basis of their conclusion that teichoic acid was distributed diffusely within the wall is therefore uncertain, particularly as the orientation of walls labelled by gold particles was not critically examined. The results reported here, however, appear to be in agreement with those of Millward \& Reaveley (1974) for $B$. licheniformis and $S$. aureus. These authors concluded that unfixed walls possessed a trilamellar density profile which was enhanced by heavy metal stains but which was related to packing of wall material and not to discrete layering of particular polymers. They also described degradation of embedded wall by uranyl stains as demonstrated by electron-lucent areas in sections. This phenomenon has been observed in our study but was related significantly to the use of glutaraldehyde fixation and not to uranyl staining. Furthermore, as uranyl exposure occurred before embedding and embedding material could be demonstrated in the electron-lucent areas, the phenomenon may be more complex than simple extraction. Clearly, interaction between specimen and embedding material may be important and the results shown in Table $I$ indicate that true density shifts may occur in sections with different staining regimens, possibly due to physical rearrangement within the section or to damage by the electron beam (Willis, 1974). We conclude that the presence of teichoic acid can be demonstrated in certain regions of the wall and that it is the polymer which binds most stain, but its contribution to contrast patterns remains uncertain.

\section{REFERENCES}

Anderson, W. A. (1968). Cytochemistry of sea-urchin gametes. II. Ruthenium red staining of gamete membranes of sea urchins. Journal of Ultrastructure Research 24, 322-333.

ARChibald, A. R. \& Coapes, H. E. (1971). The interaction of concanavalin A with teichoic acids and bacterial walls. Biochemical Journal r23, 665-667.

BADDILEY, J. (1972). Teichoic acids in cell walls and membranes of bacteria. Essays in Biochemistry 8, 35-79.

BAUER, H., FARR, D. R. \& Horisberger, M. (I974). Ultrastructural localisation of cell wall teichoic acids in Streptococcus faecalis by means of concanavalin A. Archives for Microbiology 97, 17-26.

BurdetT, I. D. J. \& Rogers, H. J. (1972). The structure and development of mesosomes studied in Bacillus licheniformis strain 6346. Journal of Ultrastructure Research 38, I $13-133$.

Chen, P. S., Toribara, J. Y. \& WARner, H. (I956). Microdetermination of phosphorus. Analytical Chemistry 28, $1756-1758$.

Cook, W. J. \& BugG, C. E. (1973). Calcium interactions with D-glucans: crystal structure of trehalosecalcium bromide monohydrate. Carbohydrate Research 3I, 265-275.

Forsberg, C. W., Wyrick, P. B., WARD, J. B. \& Rogers, H. J. (I973). The effect of phosphate limitation on the morphology and wall composition of Bacillus licheniformis and its phosphoglucoglucomutase deficient mutants. Journal of Bacteriology 113, 969-984.

GARLAND, J. M. (1974a). Preparation and performance of gold-labelled concanavalin A for the location of specifically reactive sites in walls of S. faecalis 8I9I. In Electron Microscopy and Cytochemistry, pp. 303309. Edited by E. Wisse, W. Th. Daems, I. Molenaar and P. Van Duijn. Amsterdam: North Holland/ American Elsevier.

Garland, J. M. (1974b). Staining reactions in bacterial cell walls. Proceedings, Royal Microscopical Society (London) 9, 92.

Glauert, A. \& Thornley, M. J. (I969). The topography of the bacterial cell wall. Annual Review of Microbiology 23, I 59-199. 
HigGins, M. L. \& DANEO-MOORE, L. (I972). Morphokinetic reaction of cells of Streptococcus faecalis (A.T.C.C. 9790) to specific inhibition of macromolecular synthesis; dependence of mesosome growth on deoxyribonucleic acid synthesis. Journal of Bacteriology 109, I 22 I-I 231 .

Highton, P. J. (I969). An electron microscopic study of cell growth and mesosomal structure of Bacillus licheniformis. Journal of Ultrastructure Research 26, $130-136$.

Highton, P. J., Murr, B. L., Shafa, F. \& Beer, M. (1968). Electron microscopic study of base sequence in nucleic acids. VIII. Specific conversion of thymine into anionic osmate esters. Biochemistry 7, 825-833.

Huet, C. H. \& Herzberg, M. (1973). Effects of enzymes and EDTA on ruthenium red and concanavalin A labelling of the cell surface. Journal of Ultrastructure Research 42, I86-I 99.

Huis IN'T Veld, J. H. J. \& LinsSen, W. H. (1973). The localisation of streptococcal group and type antigens: an electron microscopic study using ferritin-labelled antisera. Journal of General Microbiology 74, 315324.

Jones, D. \& Shattock, P. M. (I960). The location of the group antigen of group D Streptococcus. Journal of General Microbiology 23, 335-343.

KROPLEIN, U. (1974). Interactions of aqueous solutions of sugars with alumina. Carbohydrate Research 32 , I $67-170$.

Miller, F. (1969). Studies on the cell wall of Streptococcus faecalis 8I9I. Ph.D. thesis, University of Newcastle upon Tyne.

Millward, E. R. \& Reaveley, D. A. (1974). Electron-microscopy observations on the cell walls of some Gram-positive bacteria. Journal of Ultrastructure Research 46, 309-326.

NeIHOF, R. \& Echols, W. H. (1973). Physiochemical studies of microbial cell walls. I. Comparative electrophoretic behaviour of intact cells and isolated cell walls. Biochimica et biophysica acta 318, 23-32.

NERMUT, M. V. (1967). The ultrastructure of the cell wall of Bacillus megaterium. Journal of General Microbiology 49, 503-512.

REYNOLDS, E. S. (1963). The use of lead citrate at high pH as an electron-opaque stain in electron microscopy. Journal of Cell Biology 17, 208-212.

Ryter, A. \& Kellenberger, E. (1958). Étude au microscope electronique de plasmas contenant de l'acid desoxyribonucléique. Zeitschrift für Naturforschung 13b, 597-605.

SChleifer, K. H. \& KANDleR, O. (1972). Peptidoglycan types of bacterial cell walls and their taxonomic implications. Bacteriological Reviews 36, 407-477.

Shockman, G. D. \& Martin, J. T. (1968). Autolytic enzyme system of Streptococcus faecalis. IV. Electron microscopic observations of autolysin and lysozyme action. Journal of Bacteriology 96, I 803-1810.

Van Driel, D., Wicken, A. J., Dickson, M. R. \& Knox, K. W. (1973). Cellular location of the lipoteichoic acids of Lactobacillus fermenti NCTC 699I and Lactobacillus casei NCTC 6375. Journal of Ultrastructure Research 43, 483-497.

Weibull, C. L. (1973). Electron microscope studies on aldehyde-fixed, unstained microbial cells. Journal of Ultrastructure Research 43, I50-I 59.

Wicken, A. J. \& BadDiley, J. (I963). Structure of intracellular teichoic acids from group D Streptococci. Biochemical Journal 87, 54-62.

Willis, R. A. (1974). Electron beam-induced changes in section thickness. Proceedings, Royal Microscopical Society (London) 9, 98. 